\title{
Birth weight, early childhood growth and lung function in middle to early old age: 1946 British birth cohort
}

\author{
Yutong Cai, ${ }^{1}$ Seif O Shaheen, ${ }^{2}$ Rebecca Hardy, ${ }^{3}$ Diana Kuh, ${ }^{3}$ Anna L Hansell ${ }^{1,4}$
}

- Additional material is

published online only. To view please visit the journal online (http://dx.doi.org/10.1136/ thoraxjnl-2014-206457)

${ }^{1}$ Department of Epidemiology and Biostatistics, MRC-PHE Centre for Environment and Health, School of Public Health, Imperial College London, London, UK ${ }^{2}$ Centre for Primary Care and Public Health, Barts and The London School of Medicine and Dentistry, Queen Mary University of London, London, UK

${ }^{3}$ MRC Unit for Lifelong Health and Ageing at UCL, Institute of Epidemiology and Health Care, University College London,

London, UK

${ }^{4}$ Directorate of Public Health and Primary Care, Imperial College Healthcare NHS Trust, London, UK

\section{Correspondence to}

Dr Anna Hansell, Department of Epidemiology and

Biostatistics, MRC-PHE Centre for Environment and Health, School of Public Health, Imperial College London St Mary's Campus, Norfolk Place, London W2 1PG, UK; a.hansell@imperial.ac.uk

Received 16 October 2014 Revised 15 June 2015 Accepted 25 June 2015

Published Online First 16 July 2015

\section{ABSTRACT \\ Background Findings from previous studies}

investigating the relationship between birth weight and adult lung function have been inconsistent, and data on birth weight and adult lung function decline are lacking. Few studies have investigated the relation between early childhood growth and adult lung function.

Methods $\mathrm{FEV}_{1}$ and FVC were measured at ages 43 years, 53 years and 60-64 years in the 1946 British birth cohort study. Multiple linear regression models were fitted to study associations with birth weight and weight gain at age $0-2$ years. Multilevel models assessed how associations changed with age, with $\mathrm{FEV}_{1}$ and FVC as repeated outcomes.

Results 3276 and 3249 participants were included in $\mathrm{FEV}_{1}$ and FVC analyses, respectively. In women, there was a decreasing association between birth weight and FVC with age. From the multilevel model, for every $1 \mathrm{~kg}$ higher birth weight, FVC was higher on average by $66.3 \mathrm{~mL}(95 \% \mathrm{Cl} 0.5$ to 132$)$ at 43 years, but significance was lost at 53 years and 60-64 years. Similar associations were seen with $\mathrm{FEV}_{1}$, but linear change (decline) from age 43 years lost statistical significance after full adjustment. In men, associations with birth weight were null in multilevel models. Higher early life weight gain was associated with higher $\mathrm{FEV}_{1}$ at age 43 years in men and women combined but not in each sex.

Conclusions Birth weight is positively associated with adult lung function in middle age, particularly in women, but the association diminishes with age, potentially due to accumulating environmental influences over the life course.

\section{INTRODUCTION}

Impaired lung function is an important parameter of health and has been found to predict future morbidity and mortality from COPD and coronary heart disease, ${ }^{1} 2$ independent of other major risk factors. ${ }^{3}$ It has been postulated that adverse 'programming', as a consequence of impaired growth during critical periods in utero and early childhood, has a lasting effect on lung function and health more generally in adulthood. ${ }^{4}$

Birth weight is often used as an indicator of fetal growth. A meta-analysis of eight studies by Lawlor et $a l^{5}$ in 2005 reported that for every $1 \mathrm{~kg}$ increase in birth weight, $\mathrm{FEV}_{1}$ increased by $48 \mathrm{~mL}$ (95\% CI 26 to 70$)$. Findings across studies are inconsistent, however, with some studies reporting an

\section{Key messages}

What is the key question?

- Do associations between birth weight, early childhood growth and lung function change during midlife to early old age?

\section{What is the bottom line?}

- Early childhood growth and birth weight were associated with lung function in middle age, particularly in women, but the effect size decreased with age and no associations were seen in either sex in early old age.

\section{Why read on?}

- This is the first study reporting on whether associations between birth weight and lung function vary with age within the same individuals with repeated lung function measurements over a 20 -year period.

association, ${ }^{6-14}$ and others not. ${ }^{5} \quad 15-18$ Six $^{8} \quad 9 \quad 11-14$ studies adjusted for potential confounding factors throughout the life course, while four ${ }^{5} 15 \quad 1618$ only accounted for a limited set of potential confounders. All published studies were based on lung function measurement at a single time point and conducted in different populations at different ages. No studies to date have investigated whether the relation between birth weight and adult lung function changes longitudinally with age. Similarly, there is a paucity of data on associations between growth in early childhood and adult lung function, although two studies have reported positive associations with weight gain in the first 3 years of life $\mathrm{e}^{13}$ and in infancy, ${ }^{10}$ and higher infant weight was associated with lower mortality from COPD in men in a historical cohort study. ${ }^{6}$

The Medical Research Council National Survey of Health and Development (NSHD) (1946 British birth cohort) is one of the longest running birth cohorts worldwide with over 20 follow-ups, including spirometric lung function measurements at ages 43 years, 53 years and 60-64 years. ${ }^{19}$ We tested whether the effect of birth weight on adult lung function changes as participants age, controlling for potential confounders operating through the life course.
To cite: Cai Y, Shaheen SO, Hardy $R$, et al. Thorax 2016;71:916-922. 


\section{METHODS}

\section{Study population}

The NSHD originally recruited 16695 babies who were born in the one week of March 1946 in England, Scotland and Wales. ${ }^{19}$ All singletons born to married mothers in a non-manual or agricultural occupational social class and $25 \%$ of babies born to a manual social class were selected as the study sample $(\mathrm{N}=5362)$, consisting of 2547 women and 2815 men. Cohort members were interviewed and assessed in their own homes by trained research nurses at ages 43 years and 53 years, and at clinical research facilities (or in their homes) at 60-64 years. At the follow-up in 1989 (aged 43 years), the 1 st year in which $\mathrm{FEV}_{1}$ and FVC were measured, 3839 of the original 5362 individuals were eligible for study (365 deaths, 540 refusals, 618 emigrations), 3262 individuals $(85 \%)$ were contacted and provided data ${ }^{11}$ (figure 1). The most recent follow-up took place during 2006-2010, in which 2856 individuals of the original sample were invited to a clinic visit and 2229 (78\%) participants were interviewed by a research nurse at the clinic or in their homes. ${ }^{20}$

\section{Spirometry measurements}

More information about the spirometry protocol in NSHD is available in the online supplementary material (S1). In brief, at each follow-up, prebronchodilator (but not postbronchodilator) spirometry was carried out (standing, without nose clips) and supervised by a trained nurse using a Micro Medical Micro Plus turbine spirometer. The quality of spirometry was assessed by the nurse and formally recorded at the 1999 and 2006-2010 follow-ups. Three manoeuvres were recorded in 1989, and two in 1999 and 2006-2010, but otherwise the protocol was the same, which was developed before current ATS/ERS guidelines were published. ${ }^{21}$ As with a previous study, ${ }^{22}$ participants were excluded from the analysis if the difference between the two largest values was greater than $0.3 \mathrm{~L}^{23}$ and if values were more than 3 SD from the mean value (adjusted for sex and height). ${ }^{11}$

\section{Early life variables}

Birth weight to the nearest quarter of a pound was extracted from hospital records within a few weeks of delivery and converted to kilograms $(\mathrm{kg})$. Weight was measured by health visitors at 2 years and weight gain (g) up to age 2 years was derived by subtracting the birth weight from the weight at 2 years. Information about

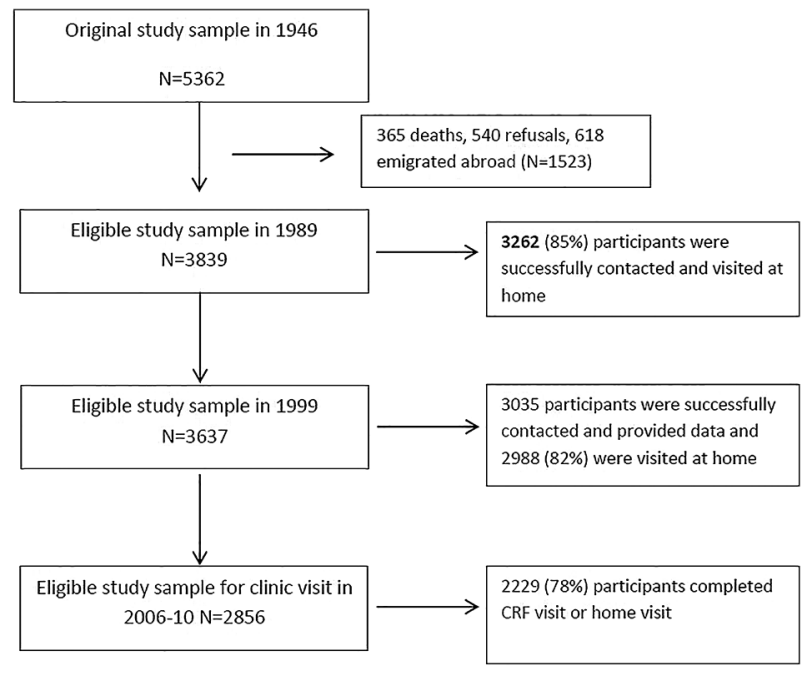

Figure 1 Flow chart of participation in the National Survey of Health and Development (NSHD) study. lower respiratory tract infections under 2 years was obtained by interviewing the child's mother in 1948 and coded as a binary variable (yes vs no). Childhood social class at 4 years was defined by father's occupation (manual vs non-manual).

\section{Adult variables}

Education qualification by age 26 years was categorised as A-level or equivalent (advanced secondary qualifications achieved at 18 years) and above, up to O-level or equivalent (secondary qualifications achieved at 16 years) and less than O-level or no qualifications. Adult standing heights at 43 years, 53 years and 60-64 years were measured to the nearest $0.1 \mathrm{~cm}$ by using a portable stadiometer. Current asthma status (yes vs no) was obtained at every age. Smoking status was obtained at each interview and expressed as a categorical variable (never, ex-smoker, current smoker) and in ever-smokers, pack-years were also calculated for each age.

\section{Statistical analysis}

3276 and 3249 participants met the inclusion criteria and were included in the $\mathrm{FEV}_{1}$ and FVC analyses, respectively. Mean (SD) lung function for categories of birth weight and current smoking status at every age was calculated. To assess the relationships between birth weight and measurements of $\mathrm{FEV}_{1}$ and FVC at every age, multiple linear regression models were fitted, with models specified a priori. Sex by birth weight interactions was investigated and analyses were conducted for both sexes and for men and women separately. A sequence of nested models was fitted: M0 - unadjusted model; M1—adjusted for current adult height; M2 - further adjusted for current adult covariates including education level, smoking status, smoking pack years and asthma status; M3-additionally adjusted for early life covariates including weight gain at 2 years, lower respiratory tract infection under 2 years and childhood social class (fully adjusted model).

Social class of head of household at every age was added to the fully adjusted model as a sensitivity analysis to address potential residual confounding by socioeconomic status.

In the next step, multilevel models were performed to assess whether the effect of birth weight on adult lung function changed with increasing age, including a random slope effect for each individual, hence accounting for the correlation between repeated measures of $\mathrm{FEV}_{1}$ and FVC. Repeated measures of $\mathrm{FEV}_{1}$ and FVC (level 1 units) were nested within the individual (level 2 units). For each of $\mathrm{FEV}_{1}$ and FVC, the change in lung function with age was modelled a priori with quadratic as well as linear terms of age to reflect the expected non-linear change in lung function with increasing age. The intercept was allowed to vary according to birth weight. Change in lung function was then allowed to vary according to birth weight by adding an age by birth weight interaction term to the model. To assess confounding, the adult height was added to the model, followed by adding time-varying adulthood covariates as well as early life covariates.

For cross-sectional and multilevel models, analyses were also restricted to those with complete data at every follow-up (complete-case analysis).

Data were analysed using Stata V.12.0 statistical package (College Station, Texas, USA).

\section{RESULTS}

As expected, mean $\mathrm{FEV}_{1}$ and $\mathrm{FVC}$ decreased with increasing age (table 1) and current smokers had lower lung function than did the ex-smokers and never smokers at all ages in both sexes. 
Table 1 Mean (SD) of FEV 1 (litres) and FVC (litres) by birth weight (gram) and current smoking status at every age

\begin{tabular}{|c|c|c|c|c|c|c|c|c|c|c|c|c|}
\hline & \multicolumn{4}{|c|}{ Age 43 years } & \multicolumn{4}{|c|}{ Age 53 years } & \multicolumn{4}{|c|}{ Age $60-64$ years } \\
\hline & $\mathrm{N}$ & $\mathrm{FEV}_{1}$ & $\mathrm{~N}$ & FVC & $N$ & $\mathrm{FEV}_{1}$ & $\mathrm{~N}$ & FVC & $\mathrm{N}$ & $\mathrm{FEV}_{1}$ & $\mathrm{~N}$ & FVC \\
\hline \multicolumn{13}{|l|}{ Men } \\
\hline Birth weight (g) & 1385 & $3.5(0.6)$ & 1326 & $4.2(0.8)$ & 1174 & $3.2(0.6)$ & 1060 & $4.1(0.7)$ & 856 & $3.1(0.6)$ & 777 & $3.9(0.7)$ \\
\hline$<2500$ & 32 & $3.3(0.6)$ & 35 & $3.9(0.9)$ & 33 & $3.1(0.6)$ & 28 & $3.8(0.7)$ & 21 & $2.9(0.6)$ & 22 & $3.7(0.7)$ \\
\hline $2500-3000$ & 214 & $3.3(0.6)$ & 192 & $4.0(0.7)$ & 168 & $3.1(0.6)$ & 169 & $3.9(0.6)$ & 122 & $3.0(0.6)$ & 107 & $3.7(0.7)$ \\
\hline $3001-3500$ & 490 & $3.5(0.6)$ & 471 & $4.2(0.8)$ & 397 & $3.2(0.6)$ & 368 & $4.1(0.7)$ & 305 & $3.1(0.5)$ & 274 & $3.8(0.7)$ \\
\hline $3501-4000$ & 467 & $3.5(0.6)$ & 465 & $4.3(0.8)$ & 411 & $3.3(0.6)$ & 360 & $4.2(0.7)$ & 304 & $3.1(0.6)$ & 281 & $3.9(0.7)$ \\
\hline$>4000$ & 182 & $3.6(0.6)$ & 163 & $4.4(0.8)$ & 165 & $3.3(0.6)$ & 135 & $4.2(0.7)$ & 104 & $3.2(0.6)$ & 93 & $3.9(0.8)$ \\
\hline Smoking & 1386 & $3.5(0.6)$ & 1328 & $4.2(0.8)$ & 1179 & $3.2(0.6)$ & 1065 & $4.1(0.7)$ & 782 & $3.1(0.6)$ & 716 & $3.9(0.7)$ \\
\hline Never smoker & 331 & $3.5(0.6)$ & 325 & $4.3(0.8)$ & 292 & $3.3(0.5)$ & 269 & $4.1(0.7)$ & 211 & $3.1(0.5)$ & 193 & $3.9(0.6)$ \\
\hline Ex-smoker & 614 & $3.6(0.6)$ & 602 & $4.3(0.8)$ & 598 & $3.3(0.6)$ & 546 & $4.1(0.7)$ & 484 & $3.1(0.6)$ & 452 & $3.9(0.7)$ \\
\hline Current smoker & 441 & $3.3(0.6)$ & 401 & $4.0(0.8)$ & 289 & $3.0(0.5)$ & 250 & $3.9(0.7)$ & 87 & $2.7(0.6)$ & 71 & $3.7(0.7)$ \\
\hline \multicolumn{13}{|l|}{ Women } \\
\hline Birth weight (g) & 1451 & $2.6(0.4)$ & 1448 & $3.1(0.6)$ & 1218 & $2.3(0.4)$ & 1175 & $2.9(0.5)$ & 932 & $2.2(0.4)$ & 911 & $2.7(0.5)$ \\
\hline$<2500$ & 57 & $2.3(0.4)$ & 58 & $2.8(0.6)$ & 45 & $2.2(0.4)$ & 44 & $2.7(0.4)$ & 30 & $2.0(0.4)$ & 31 & $2.4(0.5)$ \\
\hline $2500-3000$ & 317 & $2.5(0.4)$ & 324 & $3.0(0.6)$ & 260 & $2.3(0.4)$ & 251 & $2.8(0.5)$ & 189 & $2.2(0.4)$ & 178 & $2.7(0.5)$ \\
\hline $3001-3500$ & 538 & $2.6(0.4)$ & 541 & $3.1(0.6)$ & 458 & $2.3(0.4)$ & 446 & $2.9(0.5)$ & 354 & $2.2(0.4)$ & 354 & $2.7(0.5)$ \\
\hline $3501-4000$ & 439 & $2.6(0.4)$ & 424 & $3.2(0.6)$ & 375 & $2.4(0.4)$ & 359 & $2.9(0.5)$ & 284 & $2.2(0.4)$ & 282 & $2.8(0.5)$ \\
\hline$>4000$ & 100 & $2.6((0.5)$ & 101 & $3.2(0.6)$ & 80 & $2.3(0.4)$ & 75 & $2.8(0.5)$ & 75 & $2.2(0.4)$ & 66 & $2.7(0.5)$ \\
\hline Smoking & 1456 & $2.6(0.4)$ & 1452 & $3.1(0.6)$ & 1223 & $2.3(0.4)$ & 1180 & $2.9(0.5)$ & 856 & $2.2(0.4)$ & 833 & $2.7(0.5)$ \\
\hline Never smoker & 470 & $2.6(0.4)$ & 474 & $3.1(0.6)$ & 406 & $2.4(0.4)$ & 388 & $2.9(0.5)$ & 300 & $2.2(0.4)$ & 293 & $2.7(0.5)$ \\
\hline Ex-smoker & 567 & $2.6(0.4)$ & 569 & $3.2(0.6)$ & 541 & $2.4(0.4)$ & 532 & $2.9(0.5)$ & 475 & $2.2(0.4)$ & 465 & $2.7(0.5)$ \\
\hline Current smoker & 419 & $2.4(0.4)$ & 409 & $3.0(0.6)$ & 276 & $2.2(0.4)$ & 260 & $2.7(0.5)$ & 81 & $1.9(0.4)$ & 75 & $2.4(0.5)$ \\
\hline
\end{tabular}

In analyses of both sexes combined, neither $\mathrm{FEV}_{1}$ nor $\mathrm{FVC}$ were associated with birth weight in the fully adjusted models, except for FVC at age 53 years (table 2). A test for interaction between birth weight and sex was statistically significant for FVC at age 53 years $(\mathrm{p}=0.003)$ but not at other ages, and not at any age for $\mathrm{FEV}_{1}$.

In analyses stratified by sex, birth weight was not associated with adult lung function in men at any age except for FVC at 53 years, where in the fully adjusted model for every $1 \mathrm{~kg}$ higher in birth weight, FVC increased by $114 \mathrm{~mL}$ (95\% CI 19 to 208). However, the association was not consistently statistically significant across all confounder adjustments (table 3). In women, significant associations between birth weight and both lung function measures were seen at age 43 years in all models adjusted for adult covariates but not when further adjusted for early life covariates (table 4). In fully adjusted models, for every $1 \mathrm{~kg}$ increase in birth weight, $\mathrm{FEV}_{1}$ and FVC at 43 years increased by $51 \mathrm{~mL}(95 \% \mathrm{CI}-1$ to 103$)$ and $64 \mathrm{~mL}$ (95\% CI -5 to 133 ), respectively. No statistically significant associations were seen at age 53 years or 60-64 years.

Weight gain up to 2 years of age was significantly associated with slightly higher $\mathrm{FEV}_{1}$ but not FVC at age 43 years, for both

Table 2 Associations (coefficient and 95\% Cl) between birth weight and $\mathrm{FEV}_{1}(\mathrm{~mL})$ and $\mathrm{FVC}(\mathrm{mL})$ at every age in all persons

\begin{tabular}{|c|c|c|c|c|c|c|}
\hline \multirow{3}{*}{$\begin{array}{l}\text { Birth weight (per } 1 \text { kg increase) } \\
\text { M0: unadjusted }\end{array}$} & \multicolumn{6}{|c|}{$\mathrm{FEV}_{1}(\mathrm{~mL})$} \\
\hline & \multicolumn{2}{|c|}{ Age 43 years $(\mathrm{N}=2836)$} & \multicolumn{2}{|c|}{ Age 53 years $(\mathrm{N}=2392)$} & \multicolumn{2}{|c|}{ Age $60-64$ years $(N=1788)$} \\
\hline & 247.3 & 198.7 to 295.8 & 214.9 & 163.2 to 266.7 & 201.7 & 139.6 to 263.8 \\
\hline M1: M0+sex & 131.9 & 94.5 to 169.3 & 91.9 & 52.9 to 130.8 & 106.8 & 60.3 to 153.2 \\
\hline M2:M1+adult height* & 39.3 & 3.8 to 74.9 & -2.6 & -39.1 to 34.0 & 6.8 & -38.0 to 51.7 \\
\hline M3: M2+adult covariatest & 25.7 & -13.5 to 64.8 & 17.7 & -21.9 to 57.3 & 22.3 & -29.0 to 73.7 \\
\hline \multirow[t]{2}{*}{ M4: M3+early life covariates $\ddagger$} & 42.4 & -2.3 to 87.0 & 31.6 & -13.3 to 76.5 & 39.4 & -18.1 to 96.8 \\
\hline & \multicolumn{6}{|c|}{ FVC (mL) } \\
\hline Birth weight (per $1 \mathrm{~kg}$ increase) & \multicolumn{2}{|c|}{ Age 43 years $(N=2774)$} & \multicolumn{2}{|c|}{ Age 53 years $(\mathrm{N}=2235)$} & \multicolumn{2}{|c|}{ Age $60-64$ years $(\mathrm{N}=1688)$} \\
\hline M0: unadjusted & 330.8 & 266.5 to 395.0 & 297.3 & 227.7 to 366.9 & 239.8 & 159.7 to 319.8 \\
\hline M1: M0+sex & 188.4 & 137.1 to 239.6 & 154.4 & 104.0 to 204.8 & 112.3 & 54.2 to 170.4 \\
\hline M2: M1+adult height* & 59.7 & 11.3 to 108.1 & 26.1 & -19.6 to 71.8 & -31.2 & -85.2 to 22.8 \\
\hline M3: M2+adult covariates $†$ & 34.4 & -20.0 to 88.8 & 37.3 & -15.0 to 89.6 & -20.4 & -84.5 to 43.7 \\
\hline M4: M3+early life covariatesł & 43.1 & -18.6 to 104.7 & 60.7 & 2.1 to 119.3 & -13.2 & -85.7 to 59.3 \\
\hline
\end{tabular}


Table 3 Associations (coefficient and 95\% Cl) between birth weight and $\mathrm{FEV}(\mathrm{mL})$ and $\mathrm{FVC}(\mathrm{mL})$ at age 43 years, 53 years and60-64 years in men

\begin{tabular}{|c|c|c|c|c|c|c|}
\hline \multirow{3}{*}{$\begin{array}{l}\text { Men } \\
\text { Birth weight (per } 1 \text { kg increase) } \\
\text { M0: unadjusted }\end{array}$} & \multicolumn{6}{|c|}{$\mathrm{FEV}_{1}(\mathrm{~mL})$} \\
\hline & \multicolumn{2}{|c|}{ Age 43 years $(\mathrm{N}=1385)$} & \multicolumn{2}{|c|}{ Age 53 years $(\mathrm{N}=1174)$} & \multicolumn{2}{|c|}{ Age $60-64$ years $(N=856)$} \\
\hline & 128.0 & (67.7 to 188.4 ) & 110.7 & (49.8 to 171.6 ) & 136.1 & (60.6 to 211.6$)$ \\
\hline M1: M0+adult height* & 17.6 & $(-40.4$ to 75.5$)$ & 2.1 & $(-55.6$ to 59.7$)$ & 8.9 & $(-64.7$ to 82.5$)$ \\
\hline M2: M1+adult covariatest & 1.1 & $(-63.2$ to 65.4$)$ & 26.3 & $(-35.6$ to 88.2$)$ & 27.4 & $(-55.2$ to 109.9$)$ \\
\hline \multirow{2}{*}{ M3: M2+early life covariatesł } & 28.4 & $(-44.9$ to 101.7$)$ & 34.6 & $(-35.2$ to 104.3$)$ & 63.0 & $(-31.2$ to 157.2$)$ \\
\hline & \multicolumn{6}{|c|}{ FVC (mL) } \\
\hline Birth weight (per $1 \mathrm{~kg}$ increase) & \multicolumn{2}{|c|}{ Age 43 years $(N=1326)$} & \multicolumn{2}{|c|}{ Age 53 years $(N=1060)$} & \multicolumn{2}{|c|}{ Age $60-64$ years $(\mathrm{N}=777)$} \\
\hline M0: unadjusted & 187.7 & (103.1 to 272.2 ) & 224.6 & (143.8 to 305.5 ) & 128.3 & (31.7 to 224.9 ) \\
\hline M1: M0+adult height* & 30.1 & $(-50.2$ to 110.5$)$ & 66.8 & $(-7.55$ to 141.1$)$ & -50.5 & $(-141.2$ to 40.3$)$ \\
\hline M2: M1+adult covariatest & -3.8 & $(-95.7$ to 88.1$)$ & 74.4 & $(-11.8$ to 160.7$)$ & -15.3 & $(-123.2$ to 92.6$)$ \\
\hline M3: M2+early life covariatesł & 10.8 & $(-93.4$ to 115.1$)$ & 113.6 & (19.2 to 208.0$)$ & 23.4 & $(-101.9$ to 148.7$)$ \\
\hline
\end{tabular}

sexes combined (table 5). In a fully adjusted model, each $1 \mathrm{~kg}$ higher weight gain up to age 2 years was associated with $17 \mathrm{~mL}$ (95\% CI 0.7 to 33 ) higher $\mathrm{FEV}_{1}$ at age 43 years. Significant associations were neither seen at older ages, nor in analyses stratified by sex.

In the multilevel analysis, birth weight had a strong effect in women on $\mathrm{FEV}_{1}$ and $\mathrm{FVC}$ levels at age 43 years and on the linear change in both measures between 43 years and 60-64 years (table 6), with results showing decreasing size of associations with increasing age. The intercepts were reduced after adjustments for height, adulthood and early life covariates, but the estimates for linear change in women remained consistently stable except that the association of birth weight on reduced decline in $\mathrm{FEV}_{1}$ became non-significant after adjustment for childhood factors. In women, estimates from the fully adjusted model show that for every $1 \mathrm{~kg}$ higher birth weight, $\mathrm{FEV}_{1}$ was higher on average by $61.9 \mathrm{~mL}$ (95\% CI 11.4 to 112.4 ) at 43 years, by $43.9 \mathrm{~mL}(95 \% \mathrm{CI}-2.8$ to 90.6$)$ at 53 years and $25.9 \mathrm{~mL}(95 \%$ $\mathrm{CI}-28.0$ to 79.8$)$ at 63 years. Corresponding figures for FVC were $66.3 \mathrm{~mL}(95 \% \mathrm{CI} 0.5$ to 132$)$ at 43 years, $25.7 \mathrm{~mL}(95 \%$ $\mathrm{CI}-30$ to 82$)$ at 53 years and $-15 \mathrm{~mL}(95 \% \mathrm{CI}-82$ to 52$)$ at 63 years. The effect of per $1 \mathrm{~kg}$ higher birth weight on adult FVC level decreased by about $80 \mathrm{~mL}$ in 20 years, thus supporting the individual regression model results (table 4). In men, no changes with age were observed in terms of effect of birth weight on either $\mathrm{FEV}_{1}$ or FVC.

\section{Sensitivity analyses}

Further adjusting for social class of head of household did not materially change the effect estimates (data not shown). Approximately $50 \%$ of the 3262 participants at age 43 years had valid $\mathrm{FEV}_{1}(\mathrm{~N}=1730)$ and FVC $(\mathrm{N}=1736)$ measurements at each of the three ages. There were 626 individuals who had lung function data at age 43 years but not 53 years, and 919 individuals with data at 53 years but not 60-64 years. A further 454 had missing covariates information giving a sample of 1276 (560 men and 716 women) for complete case analysis. There were no associations found in adjusted models between birth

Table 4 Associations (coefficient and $95 \% \mathrm{Cl}$ ) between birth weight and $\mathrm{FEV}_{1}(\mathrm{~mL})$ and $\mathrm{FVC}(\mathrm{mL})$ at age 43 years, 53 years and 60-64 years in women

\begin{tabular}{|c|c|c|c|c|c|c|}
\hline \multirow{3}{*}{$\begin{array}{l}\text { Women } \\
\text { Birth weight (per } 1 \mathrm{~kg} \text { increase) } \\
\text { M0: unadjusted }\end{array}$} & \multicolumn{6}{|c|}{$\mathrm{FEV}_{1}(\mathrm{~mL})$} \\
\hline & \multicolumn{2}{|c|}{ Age 43 years $(\mathrm{N}=1451)$} & \multicolumn{2}{|c|}{ Age 53 years $(\mathrm{N}=1218)$} & \multicolumn{2}{|c|}{ Age $60-64$ years $(N=932)$} \\
\hline & 136.1 & (92 to 180.2 ) & 69.4 & $(21.8$ to 117.0$)$ & 76.8 & (21.8 to 131.7$)$ \\
\hline M1: M0+adult height* & 60.6 & (19.3 to 101.9$)$ & -10.7 & $(-55.1$ to 33.6$)$ & 1.8 & $(-50.6$ to 54.3$)$ \\
\hline M2: M1+adult covariatest & 46.8 & (1.7 to 92.0$)$ & 7.3 & $(-41.9$ to 56.4$)$ & 13.7 & $(-47.7$ to 75.2$)$ \\
\hline \multirow[t]{2}{*}{ M3: M2+early life covariates } & 51.0 & $(-1.2$ to 103.2$)$ & 29.9 & $(-26.3$ to 86.1$)$ & 19.8 & $(-47.7$ to 87.2$)$ \\
\hline & \multicolumn{6}{|c|}{ FVC (mL) } \\
\hline Birth weight (per $1 \mathrm{~kg}$ increase) & \multicolumn{2}{|c|}{ Age 43 years $(\mathrm{N}=1448)$} & \multicolumn{2}{|c|}{ Age 53 years $(\mathrm{N}=1175)$} & \multicolumn{2}{|c|}{ Age $60-64$ years $(N=911)$} \\
\hline M0: unadjusted & 189 & (129.8 to 248.3 ) & 79.7 & (19.2 to 140.2$)$ & 96.4 & (28.7 to 164$)$ \\
\hline M1: M0+adult height* & 86.8 & (31.3 to 142.3 ) & -19.6 & (-73.7 to 34.6$)$ & -16.9 & $(-79.0$ to 45.1$)$ \\
\hline M2: M1+adult covariatest & 63.9 & (2.6 to 125.1$)$ & -4.5 & (-66.2 to 57.2$)$ & -23.1 & $(-96.0$ to 49.9$)$ \\
\hline M3: M2+early life covariatesł & 64.2 & $(-5.0$ to 133.3$)$ & 2.3 & $(-68.3$ to 72.9$)$ & -31.4 & $(-111.7$ to 49.0$)$ \\
\hline
\end{tabular}


Table 5 Associations (coefficient and $95 \% \mathrm{Cl}$ ) between weight gain up to age 2 years and $\mathrm{FEV}_{1}(\mathrm{~mL})$ and $\mathrm{FVC}(\mathrm{mL})$ at age 43 years, 53 years and 60-64 years in men and women: fully adjusted model*

\begin{tabular}{|c|c|c|c|c|c|c|}
\hline \multirow{3}{*}{$\begin{array}{l}\text { All persons } \\
\text { Weight gain up to } 2 \text { years of age (per } 1 \mathrm{~kg} \text { increase) }\end{array}$} & \multicolumn{6}{|c|}{$\mathrm{FEV}_{1}(\mathrm{~mL})$} \\
\hline & \multicolumn{2}{|c|}{ Age 43 years $(\mathrm{N}=2836)$} & \multicolumn{2}{|c|}{ Age 53 years $(\mathrm{N}=2392)$} & \multicolumn{2}{|c|}{ Age $60-64$ years $(\mathrm{N}=1788)$} \\
\hline & 17.1 & (0.7 to 33.5$)$ & 4.8 & $(-11.7$ to 21.3$)$ & 10.8 & $(-9.0$ to 30.6$)$ \\
\hline & \multicolumn{6}{|c|}{ FVC (mL) } \\
\hline & \multicolumn{2}{|c|}{ Age 43 years $(N=2774)$} & \multicolumn{2}{|c|}{ Age 53 years $(\mathrm{N}=2235)$} & \multicolumn{2}{|c|}{ Age $60-64$ years $(\mathrm{N}=1688)$} \\
\hline \multirow[t]{2}{*}{ Weight gain up to 2 years of age (per $1 \mathrm{~kg}$ increase) } & 10.6 & $(-11.8$ to 33.1$)$ & 13.0 & $(-8.0$ to 34.0$)$ & 1.4 & (-23.9 to 26.7$)$ \\
\hline & \multicolumn{6}{|c|}{$\mathrm{FEV}_{1}(\mathrm{~mL})$} \\
\hline Men & \multicolumn{2}{|c|}{ Age 43 years $(N=1385)$} & \multicolumn{2}{|c|}{ Age 53 years $(\mathrm{N}=1174)$} & \multicolumn{2}{|c|}{ Age $60-64$ years $(\mathrm{N}=856)$} \\
\hline \multirow[t]{3}{*}{ Weight gain up to 2 years of age (per $1 \mathrm{~kg}$ increase) } & 20.3 & $(-7.2$ to 47.7$)$ & -3.6 & $(-30.0$ to 22.9$)$ & 30.9 & $(-2.7$ to 64.6$)$ \\
\hline & \multicolumn{6}{|c|}{$\mathrm{FVC}(\mathrm{mL})$} \\
\hline & \multicolumn{2}{|c|}{ Age 43 years $(\mathrm{N}=1326)$} & \multicolumn{2}{|c|}{ Age 53 years $(\mathrm{N}=1060)$} & \multicolumn{2}{|c|}{ Age $60-64$ years $(\mathrm{N}=777)$} \\
\hline \multirow[t]{2}{*}{ Weight gain up to 2 years of age (per $1 \mathrm{~kg}$ increase) } & 2.5 & $(-35.4$ to 40.4$)$ & 24.5 & $(-9.8$ to 58.8$)$ & 34.7 & $(-11.8$ to 81.3$)$ \\
\hline & \multicolumn{6}{|c|}{$\mathrm{FEV}_{1}(\mathrm{~mL})$} \\
\hline Women & \multicolumn{2}{|c|}{ Age 43 years $(\mathrm{N}=1451)$} & \multicolumn{2}{|c|}{ Age 53 years $(\mathrm{N}=1218)$} & \multicolumn{2}{|c|}{ Age $60-64$ years $(\mathrm{N}=932)$} \\
\hline \multirow[t]{3}{*}{ Weight gain up to 2 years of age (per $1 \mathrm{~kg}$ increase) } & 15.6 & $(-3.1$ to 34.3$)$ & 13.4 & $(-6.4$ to 33.1$)$ & -1.0 & $(-23.2$ to 21.2$)$ \\
\hline & \multicolumn{6}{|c|}{$\mathrm{FVC}(\mathrm{mL})$} \\
\hline & \multicolumn{2}{|c|}{ Age 43 years $(\mathrm{N}=1448)$} & \multicolumn{2}{|c|}{ Age 53 years $(\mathrm{N}=1175)$} & \multicolumn{2}{|c|}{ Age $60-64$ years $(\mathrm{N}=911)$} \\
\hline Weight gain up to 2 years of age (per $1 \mathrm{~kg}$ increase) & 23.6 & $(-1.5$ to 48.8$)$ & 5.8 & $(-19.0$ to 30.6$)$ & -15.5 & $(-41.9$ to 10.9$)$ \\
\hline
\end{tabular}

weight and $\mathrm{FEV}_{1}$ and FVC at all ages in men or women in the complete-case analysis (see online supplementary S2a and S2b), while results from the complete-case multilevel model analysis were broadly comparable to those presented in table 6 ; in particular the linear change for $\mathrm{FEV}_{1}$ and $\mathrm{FVC}$ in women remained similar (see online supplementary S3).

\section{DISCUSSION}

To our knowledge, this is the first study to explore the associations between birth weight, early growth and adult lung function over time with repeated measurements. In women, after adjusting for adult height and other potential confounders in adult life, higher birth weight remained positively associated

Table 6 Associations (coefficient and $95 \% \mathrm{Cl}$ ) between birth weight and $\mathrm{FEV}_{1}(\mathrm{~mL})$ and $\mathrm{FVC}(\mathrm{mL})$ change from ages 43 years to $60-64$ years (multilevel model)

\begin{tabular}{|c|c|c|c|c|c|c|c|c|}
\hline \multirow[b]{2}{*}{ Men } & \multicolumn{4}{|c|}{ FEV1 $(\mathrm{N}=1640)$} & \multicolumn{4}{|c|}{ FVC $(\mathrm{N}=1609)$} \\
\hline & \multicolumn{2}{|c|}{ Age 43 years $(\mathrm{mL})$} & \multicolumn{2}{|c|}{$\begin{array}{l}\text { Linear change from age } \\
43 \text { years, ( } \mathrm{mL} / \text { year) }\end{array}$} & \multicolumn{2}{|c|}{ Age 43 years $(\mathrm{mL})$} & \multicolumn{2}{|c|}{$\begin{array}{l}\text { Linear change from age } \\
43 \text { years, (mL/year) }\end{array}$} \\
\hline \multicolumn{9}{|l|}{ Birth weight (per $1 \mathrm{~kg}$ increase) } \\
\hline M0: age, quadratic age, age* birth weight & 131.6 & (75.6 to 187.6$)$ & 0.3 & $(-2.2$ to 2.8$)$ & 198.2 & (119.6 to 276.8 ) & -1.1 & $(-5.5$ to 3.3$)$ \\
\hline $\mathrm{M} 1: \mathrm{M} 0+$ adult height & 31.9 & $(-21.4$ to 85.2$)$ & 0.2 & $(-2.4$ to 2.7$)$ & 50.3 & $(-23.7$ to 124.3$)$ & -1.8 & $(-6.2$ to 2.6$)$ \\
\hline M2: M1+adult covariates $t$ & 24.7 & $(-35.3$ to 84.8$)$ & 2.0 & $(-0.9$ to 5.0$)$ & 18.6 & $(-66.7$ to 103.8$)$ & 2.0 & $(-3.1$ to 7.1$)$ \\
\hline \multirow[t]{2}{*}{ M3: M2+early life covariates* } & 50.0 & $(-17.5$ to 117.6$)$ & 1.9 & $(-1.4$ to 5.2$)$ & 42.9 & $(-52.4$ to 138.1$)$ & 2.4 & $(-3.4$ to 8.1$)$ \\
\hline & \multicolumn{4}{|c|}{$\mathrm{FEV}_{1}(\mathrm{~N}=1636)$} & \multicolumn{4}{|c|}{ FVC $(\mathrm{N}=1640)$} \\
\hline Women & \multicolumn{2}{|c|}{ Age 43 years $(\mathrm{mL})$} & \multicolumn{2}{|c|}{$\begin{array}{l}\text { Linear change from age } \\
43 \text { years, ( } \mathrm{mL} / \text { year) }\end{array}$} & \multicolumn{2}{|c|}{ Age 43 years $(\mathrm{mL})$} & \multicolumn{2}{|c|}{$\begin{array}{l}\text { Linear change from age } \\
43 \text { years, (mL/year) }\end{array}$} \\
\hline \multicolumn{9}{|l|}{ Birth weight (per $1 \mathrm{~kg}$ increase) } \\
\hline M0: age, quadratic age, age ${ }^{*}$ birth weight & 131.4 & (88.7 to 174.0$)$ & -2.5 & $(-4.3$ to -0.7$)$ & 184.4 & (127.4 to 241.3 ) & -4.5 & $(-7.2$ to -1.7$)$ \\
\hline $\mathrm{M} 1: \mathrm{M} 0+$ adult height & 60.6 & (21.0 to 100.1$)$ & -2.6 & $(-4.4$ to -0.8$)$ & 81.4 & (28.9 to 134.0$)$ & -5.0 & $(-7.8$ to -2.3$)$ \\
\hline M2: M1+adult covariates $\dagger$ & 58.0 & (13.7 to 102.4$)$ & -2.4 & $(-4.5$ to -0.3$)$ & 69.0 & (10.1 to 127.9 ) & -4.8 & $(-7.9$ to -1.5$)$ \\
\hline M3: M2+early life covariates* & 61.9 & (11.4 to 112.4$)$ & -1.8 & $(-4.1$ to 0.5$)$ & 66.3 & $(0.5$ to 132.1$)$ & -4.1 & $(-7.6$ to -0.5$)$ \\
\hline
\end{tabular}


with higher $\mathrm{FEV}_{1}$ and $\mathrm{FVC}$ at 43 years; however, the size of the associations decreased with age in linear regression analyses and this was confirmed in the multilevel analysis. In men, higher birth weight was only associated with FVC at 53 years after adjustment for adult height and other confounders and significance was sensitive to confounders included in the model and no effect was seen in multilevel models. Higher weight gain in early life was only associated with higher $\mathrm{FEV}_{1}$ at age 43 years in combined analyses but not when stratified by sex, nor at older ages.

Multilevel models using repeated measures allow effective statistical evaluation with missing outcome data under the assumption that these data are missing at random. ${ }^{24}$ The results from these analyses suggesting a weakening association with birth weight with age, could alternatively be interpreted that higher birth weight was associated with faster absolute declines in $\mathrm{FEV}_{1}$ and $\mathrm{FVC}$ in women. Using this interpretation, women with a higher birth weight showed faster absolute declines in $\mathrm{FEV}_{1}$ than did those with a lower birth weight, by $1.8 \mathrm{~mL}(95 \%$ CI -0.5 to 4.1) per year per kg higher birth weight, albeit from a higher starting point at age 43 years $\left(\mathrm{FEV}_{1}\right.$ was higher by $61.9 \mathrm{~mL}$ (95\% CI 11.4 to 112.4$)$ per kg higher birth weight). They also showed a faster decline in FVC of $4.1 \mathrm{~mL}(95 \%$ CI 0.5 to 7.6) per year per kg higher birth weight. We find this a less intuitive interpretation than that of a weakening association between birth weight and lung function over time, particularly as those who were healthier and of higher adult socioeconomic position are more likely to have remained in the NSHD study over time. $^{25}$

We speculate that while early growth is more likely to influence peak attainment of $\mathrm{FEV}_{1}$ and $\mathrm{FVC}$ as a young adult, ${ }^{26}$ as life progresses adulthood factors such as smoking, respiratory illness, body size ${ }^{27} \operatorname{diet}^{28}$ or environmental air pollution ${ }^{29}$ start to play greater roles. Additionally, normal age-related decline in lung function starts in midlife and the rate rapidly increases as people age, ${ }^{30}$ which might also weaken the effect of birth weight on lung function.

Our findings on birth weight and lung function are broadly consistent with previous studies that have examined individuals at single time points. Most of these studies were in individuals $<50$ years and found significant associations between birth weight and either $\mathrm{FEV}_{1}{ }^{8} 122631$ only or $\mathrm{FEV}_{1}$ and FVC, ${ }^{7-11}$ 1314 but some found no associations with either $\mathrm{FEV}_{1}$ or FVC. ${ }^{16-18}$ Where studies were stratified by sex, two studies in adults aged 20-28 years, found associations with $\mathrm{FEV}_{1}$ in men only ${ }^{31}$ in one study and both sexes in the other ${ }^{26}$ but no associations with FVC; two studies of adults with mean age in the late 40s reported significant positive associations of birth weight with $\mathrm{FEV}_{1}$ and $\mathrm{FVC}^{79}$ in men and women. Of three studies examining birth weight and lung function at $>50$ years of age, ${ }^{56}{ }^{15}$ two studies did not find an association-a small $(\mathrm{N}=240)$ Scottish study $^{15}$ with mean age of 57.6 years and a study of British women aged 60-79 years ${ }^{5}$-but a study of English men with mean age of 64 years $^{6}$ did. Discrepancies with the present study might arise through differences in confounder adjustment and cohorts and the small sample size in some other studies.

We stratified the analysis by sex because biological, environmental and sociocultural factors may affect airway function differentially in men and women across life. ${ }^{32}$ It is proposed that sex is an important determinant of airway diseases and therefore should be considered in clinical and epidemiological research. ${ }^{33}$ Different results in men and women may relate to faster accumulation of environmental insults in men of this age, such that impact of early life factors would be obscured in men at a younger age than in women. Men born in 1946 were more likely (1) to smoke (and smoke heavily) and to be exposed to environmental tobacco smoke and (2) to have higher occupational exposures to dust, gases and fumes than women. We cannot readily explain the isolated significant association of birth weight with FVC observed in this study in men at age 53 years but this is not inconsistent with there being a small association across all ages.

Early life growth potentially affects a crucial stage of lung growth and development, and the numbers of alveoli are known to increase in early life up to around 2 years of age in both sexes. ${ }^{34}$ Few other studies have examined associations between early growth and lung function, with mixed findings. Similar effect sizes of 1st year weight gain on $\mathrm{FEV}_{1}$ and FVC were seen in women aged 31 years to those in the present study, but the study also found associations with FVC in men. ${ }^{10}$ Another study ${ }^{13}$ of 1037 adults aged 32 years found that weight gain by age 3 years was not significantly associated with either $\mathrm{FEV}_{1}$ or FVC in combined analysis (men and women), but FVC was associated with early weight gain in men only.

A major strength of our study is the regular follow-ups of individuals in this population-based cohort from birth into late adult life, with data collected on potential confounders and mediating factors across life, and repeated lung function measurements from midlife to early old age. The repeated measures design and hierarchical multilevel modelling approach in the analyses better account for measurement errors and increase power to detect effects.

This study has certain limitations. As with most previous studies, birth weight is the only measure available as a proxy of fetal growth in this cohort. Hancox et $a l^{13}$ reported that body mass index (BMI) at birth or ponderal index may be slightly better than birth weight as a predictor of lung function at age 32 years. However, in another study, neither birth length nor ponderal index was related to lung function at age 25 years, but birth weight was. ${ }^{31}$ Furthermore, the rounding of the original birth weight measurements may have led to underestimation of associations with lung function, assuming misclassification of birth weight was random with respect to lung function. Information on gestational age at birth was not available in 1946, but significant associations remained after adjusting for gestational age in previous studies. ${ }^{8-10} 131431$ Also, we have no information on maternal smoking and dietary patterns across life and during pregnancy, two factors that may impact on fetal growth; ${ }^{35} 36$ however, previous studies ${ }^{89}$ have demonstrated that the explored relationship was independent of maternal smoking during pregnancy. Effect estimates were substantially reduced after adjusting for adult height, an important determinant of adult lung function but also partly explained by birth weight-babies with higher birth weights became taller adults with bigger lungs. ${ }^{37}$

As expected in a very long-running cohort there was some differential loss over time of participants with lower educational attainment and lifelong smokers that has been previously documented. ${ }^{20}$ This bias might be expected to lead to an underestimate of the overall decline in lung function and potentially lower accumulation of environmental insults from occupational sources and active or passive smoking. However, as the NSHD still remains broadly nationally representative in terms of occupational social class and unemployment profile, we think any impact on the associations presented is likely to be small. Further, the complete-case analysis showed comparable results for the multilevel models (see online supplementary S3).

In conclusion, our results suggest that while birth weight and early life factors are associated with lung function in middle 
age, particularly in women, their impact decreases over time as other risk factors accumulate over the life course.

Acknowledgements The authors thank all study members of NSHD and NSHD scientific and data collection teams.

Contributors Study design: YC, SOS, RH, DK and ALH. Data analysis: YC and ALH. Drafted and edited the paper: YC, SOS and ALH. Discussed and interpreted the findings: YC, SOS, RH, DK and ALH. Cohort data collection: RH, DK and the NSHD scientific and data collection team. All authors have revised the paper and approved the final version.

Funding The NSHD and Professors RH and DK are supported by core funding and grant funding (MC_UU_12019/1, MC_UU_12019/2, MC_UU_12019/4) from the UK Medical Research Council.

Competing interests None declared.

Patient consent Obtained.

Ethics approval Greater Manchester Local Research Ethics Committee (approval 07/H1008/245) and the Scotland A Research Ethics Committee.

Provenance and peer review Not commissioned; externally peer reviewed.

\section{REFERENCES}

1 Mannino DM, Buist AS, Petty TL, et al. Lung function and mortality in the United States: data from the First National Health and Nutrition Examination Survey follow up study. Thorax 2003;58:388-93.

2 Sin DD, Wu L, Man SF. The relationship between reduced lung function and cardiovascular mortality: a population-based study and a systematic review of the literature. Chest 2005;127:1952-9.

3 Ostrowski S, Barud W. Factors influencing lung function: are the predicted values for spirometry reliable enough? J Physiol Pharmacol 2006;57(Suppl 4):263-71.

4 Barker DJP. Mothers, babies and health in later life. Edinburgh: Churchill Livingstone, 1998.

5 Lawlor DA, Ebrahim S, Davey Smith G. Association of birth weight with adult lung function: findings from the British Women's Heart and Health Study and a meta-analysis. Thorax 2005:60:851-8.

6 Barker DJ, Godfrey KM, Fall C, et al. Relation of birth weight and childhood respiratory infection to adult lung function and death from chronic obstructive airways disease. BMJ 1991;303:671-5.

7 Stein $\mathrm{CE}$, Kumaran $\mathrm{K}$, Fall $\mathrm{CH}$, et al. Relation of fetal growth to adult lung function in south India. Thorax 1997;52:895-9.

8 Boezen HM, Vonk JM, van Aalderen WM, et al. Perinatal predictors of respiratory symptoms and lung function at a young adult age. Eur Respir J 2002;20:383-90.

9 Edwards CA, Osman LM, Godden DJ, et al. Relationship between birth weight and adult lung function: controlling for maternal factors. Thorax 2003;58:1061-5.

10 Canoy D, Pekkanen J, Elliott $\mathrm{P}$, et al. Early growth and adult respiratory function in men and women followed from the fetal period to adulthood. Thorax 2007;62:396-402.

11 Orfei L, Strachan DP, Rudnicka AR, et al. Early influences on adult lung function in two national British cohorts. Arch Dis Child 2008;93:570-4.

12 Tennant PW, Gibson GJ, Pearce MS. Lifecourse predictors of adult respiratory function: results from the Newcastle Thousand Families Study. Thorax 2008;63:823-30

13 Hancox RJ, Poulton R, Greene JM, et al. Associations between birth weight, early childhood weight gain and adult lung function. Thorax 2009;64:228-32.
14 Pei L, Chen G, Mi J, et al. Low birth weight and lung function in adulthood: retrospective cohort study in China, 1948-1996. Pediatrics 2010;125:e899-905.

15 Shaheen SO, Sterne JA, Tucker JS, et al. Birth weight, childhood lower respiratory tract infection, and adult lung function. Thorax 1998;53:549-53.

16 Lopuhaa CE, Roseboom TJ, Osmond C, et al. Atopy, lung function, and obstructive airways disease after prenatal exposure to famine. Thorax 2000;55:555-61.

17 Laerum BN, Svanes C, Gulsvik A, et al. Is birth weight related to lung function and asthma symptoms in Nordic-Baltic adults? Respir Med 2004;98:611-18.

18 Bua J, Prescott E, Schack-Nielsen L, et al. Weight history from birth through childhood and youth in relation to adult lung function, in Danish juvenile obese and non-obese men. Int J Obes (Lond) 2005;29:1055-62.

19 Kuh D, Pierce M, Adams J, et al. Cohort profile: updating the cohort profile for the MRC National Survey of Health and Development: a new clinic-based data collection for ageing research. Int J Epidemiol 2011;40:e1-9.

20 Stafford M, Black S, Shah I, et al. Using a birth cohort to study ageing: representativeness and response rates in the National Survey of Health and Development. Eur J Ageing 2013;10:145-57.

21 Miller MR, Hankinson J, Brusasco V, et al. Standardisation of spirometry. Eur Respir J 2005;26:319-38.

22 Schikowski T, Adam M, Marcon A, et al. Association of ambient air pollution with the prevalence and incidence of COPD. Eur Respir J 2014;44:614-26.

23 Quanjer PH. Standardized lung function testing. Bull Eur Physiopathol Respir 1983;19(Suppl 5):1-95.

24 Hardy R, Kuh D, Langenberg C, et al. Birthweight, childhood social class, and change in adult blood pressure in the 1946 British birth cohort. Lancet 2003;362:1178-83.

25 Kuh D, Shah I, Richards M, et al. Do childhood cognitive ability or smoking behaviour explain the influence of lifetime socio-economic conditions on premature adult mortality in a British post war birth cohort? Soc Sci Med 2009:68:1565-73.

26 Suresh S, Mamun AA, O'Callaghan $\mathrm{M}$, et al. The impact of birth weight on peak lung function in young adults. Chest 2012;142:1603-10.

27 Maiolo C, Mohamed El, Carbonelli MG. Body composition and respiratory function. Acta Diabetologica 2003;40(Suppl 1):S32-8.

28 Shaheen SO, Jameson KA, Syddall HE, et al. The relationship of dietary patterns with adult lung function and COPD. Eur Respir J 2010;36:277-84.

29 Adam M, Schikowski T, Carsin AE, et al. Adult lung function and long-term air pollution exposure. ESCAPE: a multicentre cohort study and meta-analysis. Eur Respir J 2015:45:38-50.

30 Strachan DP, Sheikh A. A lifecourse approach to respiratory and allergic diseases. In: Kuh D, Ben-Shlomo Y, eds. A lifecourse approach to chronic disease epidemiology. 2nd edn. Oxford University Press, 2004:240-59.

31 Ubilla $C$, Bustos $\mathrm{P}$, Amigo $\mathrm{H}$, et al. Nutritional status, especially body mass index, from birth to adulthood and lung function in young adulthood. Ann Hum Biol 2008:35:322-33

32 Becklake MR, Kauffmann F. Gender differences in airway behaviour over the human life span. Thorax 1999;54:1119-38.

33 Baraldo S, Saetta M. Sex differences in airway anatomy over human lifespan. In: Buist S, Mapp CE, Rossi A, eds. European Respiratory Monograph 25: Respiratory Diseases in Women. 2003:1-7.

34 Merkus PJ, ten Have-Opbroek AA, Quanjer PH. Human lung growth: a review. Pediatr Pulmonol 1996;21:383-97.

35 Matsubara F, Kida M, Tamakoshi A, et al. Maternal active and passive smoking and fetal growth: a prospective study in Nagoya, Japan. J Epidemiol 2000;10:335-43.

36 Godfrey K, Robinson S, Barker DJ, et al. Maternal nutrition in early and late pregnancy in relation to placental and fetal growth. BMJ 1996;312:410-14.

37 Sorensen HT, Sabroe S, Rothman KJ, et al. Birth weight and length as predictors for adult height. Am J Epidemiol 1999;149:726-9. 